\title{
Pengaruh Waktu Distilasi Etanol-Air Terhadap Konsentrasi Overhead Product dan Bottom Product
}

The Effect of Ethanol-Water Distillation Time on the Concentration of Overhead Products and Bottom Products

\author{
Nur Ihda Farikhatin Nisa ${ }^{1 *}$, Achmad Aminudin ${ }^{2)}$ \\ ${ }^{1)}$ Universitas PGRI Madiun, Teknik Kimia \\ ${ }^{2}$ Politeknik Negeri Madiun, Mesin Otomotif \\ *email: nurihda_fn@unipma.ac.id
}

Received: 16/06/19; Revised: 17/06/19; Accepted: 25/06/19

\begin{abstract}
Abstrak
Bioetanol merupakan salah satu energi terbarukan yang dapat diproduksi dari berbagai bahan seperti sorgum, tebu atau bahkan substrat dari limbah industri makanan. Pembuatan bioetanol melibatkan proses distilasi. Tujuan dari penelitian ini adalah untuk mengetahui pengaruh lamanya waktu distilasi etanol-air terhadap konsentrasi overhead product dan bottom product yang keluar dari kolom distilasi. Metode dalam penelitian ini terdiri dari tahap persiapan, distilasi dan tahap analisa. Konsentrasi etanol ditentukan melalui pengukuran indeks bias menggunakan refraktometer. Dari hasil penelitian yang telah dilakukan dapat disimpulkan bahwa semakin besar indeks bias larutan etanol maka semakin besar konsentrasi larutan. Semakin lama waktu distilasi maka konsentrasi overhead product semakin besar. Hal ini berbanding terbalik dengan konsentrasi larutan di bottom product yang semakin kecil dengan bertambahnya waktu distilasi.
\end{abstract}

Kata kunci: bottom product, distilasi, etanol-air, overhead product

\begin{abstract}
Bioethanol is one of the renewable energies that can be produced from various materials such as sorghum, sugar cane or even substrate from industrial waste. Bioethanol production involves a distillation process. The purpose of this study was to determined the effect of ethanol-water distillation time on the concentration of overhead products and bottom products coming out of the distillation column. The method in this study consists of the preparation stage, the experimental phase and the analysis phase. Ethanol concentration was determined with measuring refractive index using refractometer. From the results it can be concluded that the greater refractive index of ethanol solution, the greater concentration of solution. Increased distillation time, make overhead products concentration increased too. This is inversely proportional to the concentration of the solution on the bottom product which is getting smaller with increasing distillation time.
\end{abstract}

Keywords: distillation, ethanol-water, overhead product, bottom product

\section{PENDAHULUAN}

Bioetanol merupakan salah satu energi terbarukan yang dapat diproduksi dari berbagai bahan seperti sorgum, tebu atau bahkan substrat dari limbah industri makanan (Sukasem dkk., 2017; Dias dkk., 2012). Bioetanol tidak hanya diproduksi dalam skala besar oleh industri tetapi juga dalam skala kecil oleh UKM atau komunitas pertanian kecil. Pembuatan 
bioetanol dari berbagai bahan tersebut dilakukan dengan proses fermentasi dan proses distilasi (Kunnakorn dkk., 2013; Afriani dkk., 2015). Proses fermentasi dilakukan dengan menggunakan biokatalis (jamur, yeast dan bateri) yang mempunyai selektivitas tinggi dalam membentuk etanol. Konsentrasi etanol dalam broth di akhir proses fermentasi berkisar antara 8$12 \%$ volume (sebagian besar adalah air dan etanol) (Afriani $d k k ., 2015)$. Kandungan etanol tersebut kemudian dipekatkan dengan proses distilasi untuk memisahkan etanol dan air, sehingga bisa dihasilkan etanol dengan kadar 95-96\% volume.

Proses distilasi adalah proses pemisahan cairan dari campurannya berdasarkan perbedaan titik didih atau kemampuan zat untuk menguap (Muhammad dkk., 2011). Produk yang mudah menguap akan naik ke bagian atas kolom distilasi dan dikondensasikan untuk menghasilkan overhead product (distilat). Sedangkan produk yang tidak menguap akan dikeluarkan sebagai bottom product (residu). Distilasi dilakukan dengan dua metode. Metode pertama yaitu mendidihkan dan mengembunkan campuran tanpa adanya refluks. Metode kedua yaitu mengembalikan sebagian kondensat ke labu distilasi sehingga terjadi kontak dengan uap yang mengalir ke kondensor (McCabe, 1993).

Proses distilasi dapat digunakan untuk memisahkan berbagai kombinasi campuran, salah satunya adalah campuran etanol-air (Zhang dkk., 2019; Alheshibri \& Craig, 2019). Faktor biaya merupakan hal yang sangat penting dalam proses ini. Banyak cara yang dapat dilakukan untuk mengoptimasi proses ini agar dapat menghemat energi dan meningkatkan efisiensi proses pemisahan (Zhao $d k k$.,
2017; Woldemariam dkk., 2017; Spotar dkk., 2015; Quijada-Maldonado dkk., 2014; Ponce $d k k$., 2015; Millare \& Basilia., 2019; Figueroa $d k k ., 2015$; Dongmin \& Yanhong, 2018; Pan $d k k .$, 2019).

Untuk mendapatkan kadar etanol yang lebih besar dari 95-96\% volume diperlukan beberapa treatment agar mendapatkan hasil yang lebih maksimal. Lamanya waktu distilasi juga merupakan salah satu faktor yang dapat menentukan efisiensi dari proses pemisahan etanol-air yang dinyatakan dalam konsentrasi overhead product dan bottom product.

Penelitian ini bertujuan untuk mengetahui pengaruh lamanya waktu distilasi etanol-air terhadap konsentrasi overhead product dan bottom product yang keluar dari kolom distilasi.

\section{METODE PENELITIAN}

Hasil akhir proses fermentasi sebagian besar adalah etanol dan air, sehingga pada penelitian ini diasumsikan campuran hanya terdiri dari etanol dan air. Penelitian dilakukan melalui 3 tahapan yang terdiri dari tahap persiapan, distilasi dan analisa.

\section{Alat dan Bahan Penelitian}

Bahan yang digunakan antara lain adalah etanol dengan kadar $47 \%$ dan aquades. Sedangkan untuk alat yang digunakan meliputi seperangkat alat distilasi, beaker glass, erlenmeyer, gelas ukur, piknometer, pipet tetes, refraktometer, timbangan elektrik dan termometer.

\section{Prosedur}

\section{Tahap Persiapan}

Langkah pertama yang dilakukan yaitu mengkalibrasi refraktometer dengan 
larutan etanol pada berbagai konsentrasi, mulai dari $10 \%$ sampai $90 \%$. Langkah yang terakhir pada tahap ini yaitu menghitung densitas dari larutan eanol yang telah dibuat.

\section{Distilasi}

Langkah pertama yaitu menyiapkan rangkaian alat distilasi dan mengisi labu distilasi dengan larutan etanol $47 \%$ sebanyak $500 \mathrm{ml}$. Selanjutnya memanaskan labu distilasi dan mengamati waktu serta temperatur overhead product pertama yang menetes sampai variasi waktu pengambilan yang telah ditentukan. Distilat (etanol) dan residu (air) diambil pada 10 menit pertama sampai proses distilasi berjalan 50 menit. Volume dan densitas dari distilat yang diperoleh kemudian diukur menggunakan piknometer. Adapun skema dari rangkaian alat distilasi pada penelitian ini ditunjukkan pada Gambar 1.

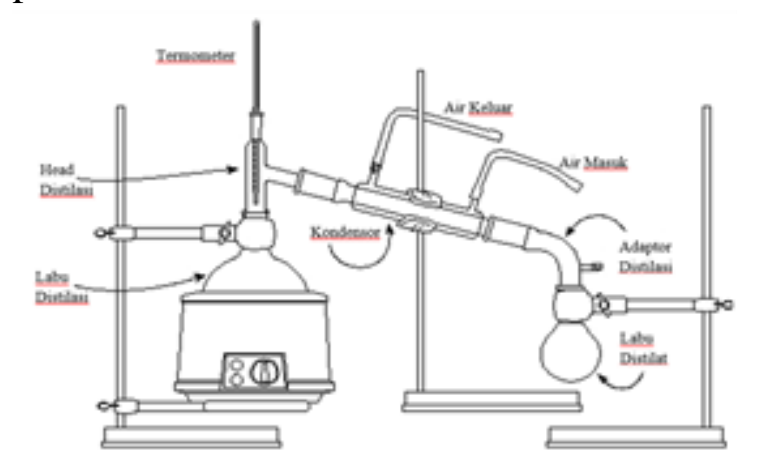

Gambar 1. Rangkaian Alat Distilasi

\section{Analisa}

Distilat dan residu yang telah diperoleh selanjutnya diukur indeks biasnya dengan menggunakan refraktometer.

\section{HASIL DAN PEMBAHASAN}

Prinsip dari distilasi yaitu menghasilkan uap dan mengembunkan kembali uap tersebut pada titik didihnya.
Titik didih suatu cairan dapat dicapai pada saat suhu dan tekanan uapnya sama dengan tekanan atmosfer ataupun lebih rendah dari tekanan atmosfer (Walangare $d k k, 2013$ ). Tujuan dari proses distilasi adalah menghasilkan cairan murni pada titik didihnya dengan memisahkannya dengan cairan lainnya yang mempunyai perbedaan titik didih. Pada distilasi sederhana, zat-zat dengan titik didih yang berdekatan menggunakan fraksinasi atau distilasi bertingkat dalam proses penyulingannya.

\section{Kurva Kalibrasi}

Kurva kalibrasi digunakan untuk menunjukkan hubungan antara konsentrasi etanol terhadap data pada pembacaan di refraktometer yang dinyatakan dengan garis lurus (regresi).

Pada tahap ini dilakukan pengukuran indeks bias dari larutan etanol pada berbagai konsentrasi. Indeks bias didefinisikan sebagai rasio cepat rambat cahaya di udara terhadap cepat rambat cahaya di larutan etanol.

Konsentrasi larutan etanol yang diukur adalah 10\%, 20\%, 30\%, 40\%, 50\%, $60 \%, 70 \%, 80 \%, 90 \%$ dan $96 \%$. Gambar 2 menunjukkan bahwa semakin besar persen volume etanol maka semakin besar pula indeks bias larutan tersebut. Pada saat persen volume $10 \%$ nilai indeks bias yang diperoleh sebesar 1,336 sedangkan pada saat persen volume $96 \%$ indeks bias sebesar 1,368. Hal ini sesuai dengan literatur yang menyebutkan bahwa peningkatan konsentrasi larutan berbanding lurus terhadap indek bias larutan tersebut (Parmitasari \& Hidayanto, 2013). 


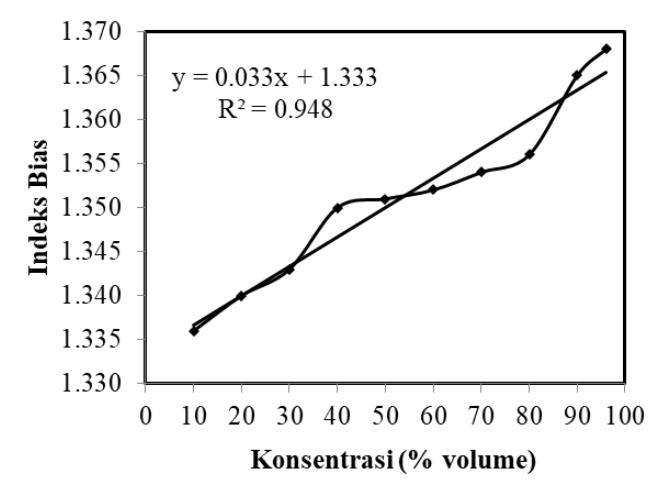

Gambar 2. Kurva Kalibrasi Etanol-Air

\section{Penentuan Konsentrasi Overhead} Product dari Kurva Kalibrasi Etanol-Air

Kurva kalibrasi indeks bias etanolair yang telah diperoleh dapat digunakan untuk menentukan konsentrasi overhead product dari kolom distilasi. Nilai indeks bias yang diperoleh untuk overhead product dan bottom product pada saat pengambilan dengan variasi waktu ditunjukkan pada tabel 1 di bawah ini.

Tabel 1. Nilai Indeks Bias pada Overhead product dan Bottom product

\begin{tabular}{ccc}
\hline \multirow{2}{*}{$\begin{array}{c}\text { Waktu } \\
\text { (menit) }\end{array}$} & \multicolumn{2}{c}{ Indeks Bias } \\
\cline { 2 - 3 } & $\begin{array}{c}\text { Overhead } \\
\text { Product }\end{array}$ & $\begin{array}{c}\text { Bottom } \\
\text { Product }\end{array}$ \\
\hline 10 & 1,353 & 1,352 \\
20 & 1,355 & 1,349 \\
30 & 1,356 & 1,347 \\
40 & 1,358 & 1,346 \\
50 & 1,361 & 1,345 \\
\hline
\end{tabular}

Pada Tabel 1 dapat dilihat bahwa nilai indeks bias yang diperoleh untuk overhead product mengalami peningkatan dengan nilai indeks bias 1,353 untuk pengambilan pada menit ke-10 menjadi 1,361 pada saat pengambilan menit ke-50. Data indeks bias tersebut digunakan untuk menentukan besarnya konsentrasi overhead product yang keluar dari kolom distilasi. Gambar 3 menunjukkan bahwa konsentrasi overhead product yang diperoleh berdasarkan kurva kalibrasi etanol-air untuk pengambilan pada saat 10 menit sampai 50 menit berturut-turut menunjukkan angka 60,606\%; 66,667\%; $69,697 \% ; 75,758 \%$ dan $84,848 \%$.

Hubungan indeks bias dengan konsentrasi larutan berbanding lurus, yaitu semakin besar indeks bias maka konsentrasi larutan yang diperoleh akan semakin besar (Parmitasari dan Hidayanto, 2013). Hal ini disebabkan karena ketika konsentrasi semakin besar maka partikelpartikel yang ada pada larutan akan semakin rapat, sehingga terjadi peningkatan kemampuan cahaya dalam menembus larutan dan menjadikan indeks bias semakin besar.

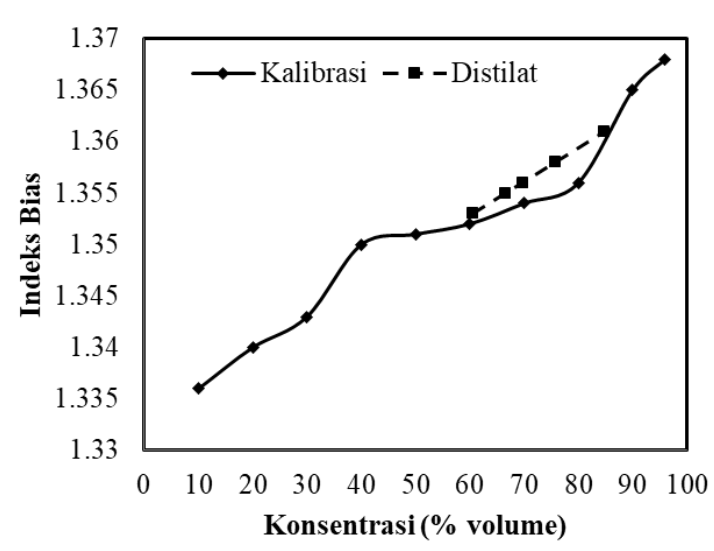

Gambar 3. Konsentrasi Overhead Product dari Kurva Kalibrasi Etanol-Air

\section{Penentuan Konsentrasi Bottom Product dari Kurva Kalibrasi Etanol-Air}

Konsentrasi bottom product juga dapat ditentukan dengan menggunakan kurva kalibrasi etanol-air. Pada Tabel 1 dapat dilihat bahwa nilai indeks bias pada bottom product mengalami penurunan dengan nilai indeks bias 1,352 untuk pengambilan pada menit ke-10 menjadi 1,345 pada saat pengambilan meit ke-50.

Semakin berkurangnya nilai indeks bias yang dihasilkan pada bottom product berbanding terbalik dengan waktu distilasi. Hal ini terjadi karena semakin banyak 
jumlah komponen etanol yang teruapkan maka komponen fraksi berat semakin berkurang, sehingga kerapatan minyak akan semakin kecil dan menyebabkan nilai indeks bias etanol pada bottom product semakin kecil.

Nilai indeks bias yang diperoleh dapat ditentukan konsentrasi bottom product berdasarkan persamaan pada kurva kalibrasi etanol-air. Gambar 4 menujukkan besarnya konsentrasi bottom product yang diperoleh pada saat pengambilan 10 menit, 20 menit, 30 menit, 40 menit dan 50 menit berturut-turut sebesar 57,576\%; 48,485\%; $42,424 \%$; 39,394\% dan 36,364\%. Hal ini sesuai dengan literatur yang menyatakan bahwa semakin pekat suatu larutan maka kerapatan cahaya semakin besar yang mana juga berbanding lurus dengan indeks bias (Parmitasari dan Hidayanto, 2013).

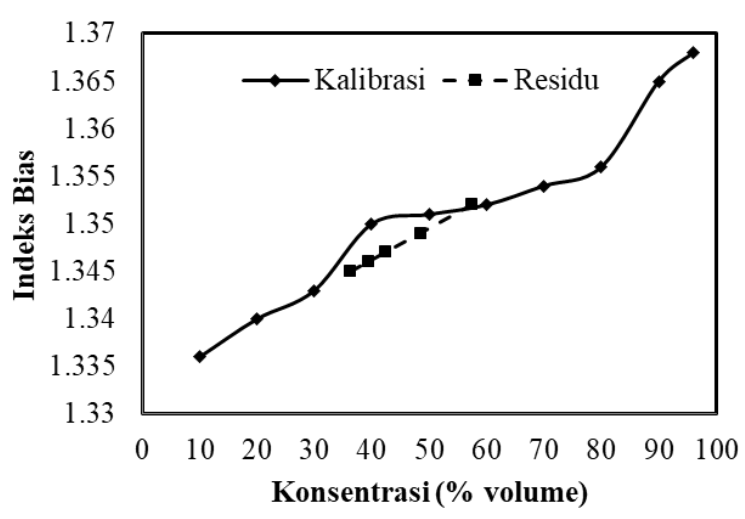

Gambar 4. Konsentrasi Bottom Product dari Kurva Kalibrasi Etanol-Air

\section{Pengaruh Waktu Distilasi terhadap} Konsentrasi Overhead Product dan Bottom Product

Lama waktu proses distilasi pada suatu campuran mempunyai peranan penting terhadap besarnya konsentrasi yang dihasilkan pada overhead product dan bottom product. Gambar 5 menunjukkan bahwa semakin lama waktu distilasi maka fraksi etanol pada overhead product akan semakin besar. Hal ini disebabkan karena lamanya waktu distilasi akan meningkatkan komponen berat etanol pada overhead product, sedangkan pada bottom product fraksi etanol yang dihasilkan semakin kecil. Pada pengambilan distilat dan residu pada 10 menit pertama hingga waktu distilasi 50 menit, diperoleh nilai indeks bias yang mengalami peningkatan dari 1,353 menjadi 1,361. Peningkatan indeks bias berbanding lurus dengan konsentrasi overhead product yang juga mengalami peningkatan dari $60,606 \%$ menjadi $84,848 \%$. Hal ini berbanding terbalik dengan konsentrasi pada bottom product yang mengalami penurunan dari konsentrasi 57,576\% untuk pengambilan pada menit ke-10 menjadi $36,364 \%$ untuk pengambilan pada menit ke-50.

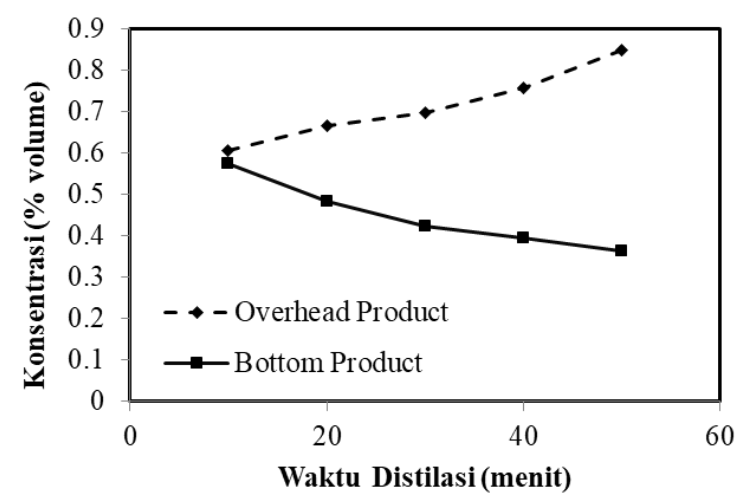

Gambar 5. Pengaruh waktu distilasi terhadap konsentrasi overhead product dan bottom product

Konsentrasi etanol yang dihasilkan dari penelitian ini lebih rendah jika dibandingkan dengan literatur yang menyatakan bahwa kadar etanol yang dihasilkan dari proses distilasi berkisar antara 95-96\% volume (Afriani $d k k$., 2015). Hal ini disebabkan karena efisiensi distilasi pada sistem ini kecil akibat dari kehilangan panas secara konduksi. Dimana kehilangan 
panas ini akan mengurangi besarnya energi kondensasi sehingga kadar etanol yang dihasilkan menjadi kecil (McCabe, 1993). Losses panas secara konduksi juga dapat disebabkan sistem isolasi pada proses distilasi yang kurang optimal sehingga efisiensi panas menjadi kecil.

\section{KESIMPULAN}

Berdasarkan penelitian distilasi etanol-air yang telah dilakukan dapat disimpulkan bahwa semakin besar indeks bias larutan etanol maka semakin besar konsentrasi larutan tersebut. Semakin lama proses distilasi maka konsentrasi overhead product semakin besar. Hal ini berbanding terbalik dengan konsentrasi larutan di bottom product yang semakin kecil dengan bertambahnya waktu distilasi.

\section{DAFTAR RUJUKAN}

Afriani, M., Gusnedi, \& Ratnawulan. (2015) Pengaruh Tinggi Kolom pada Distilasi Terhadap Kadar Bioetanol dari Tebu (Saccharum Officinarum), Pillar of Physics, 5, 25-32.

Alheshibri, M., \& Craig, V. S. J. (2019) Generation of Nanoparticles Upon Mixing Ethanol and Water; Nanobubbles or Not?, Journal of Colloid and Interface Science, 542, 136-143.

Dias, M. O. S., Junqueira, T. L., Jesus, C. D. F., Rossell, C. E. V., Filho, R. M., \& Bonomi, A. (2012) Improving Second Generation Ethanol Production Through Optimization of First Generation Production Process from Sugarcane, Energy, 43, 246-252.

Dongmin, H., \& Yanhong, C. (2018) Combining the Preconcentration Column and Recovery Column for the Extractive Distillation of Ethanol Dehydration with Low Transition Temperature Mixtures as Entrainers, Chemical Engineering and Processing: Process Intensification, 131, 203-214.

Figueroa, J. E. J., Rodrigues, M. I., \& Maciel, M. R. W. (2015) Sequential Strategy of Experimental Design I: Optimization of Extractive Distillation Process of Ethanolwater Using $[\mathrm{bmim}]\left[\mathrm{N}(\mathrm{CN})_{2}\right]$ as entrainer, Chemical Engineering and Processing: Process Intensification, 93, 56-60.

Kunnakorn, D., Rirksomboon, T., Siemanond, K., Aungkavattana, P., Kuanchertchoo, N., Chuntanalerg, P., Hemra, K., Kulprathipanja, S., James, R. B., \& Wongkasemjit, S. (2013) Techno-economic Comparison of Energy Usage Between Azeotropic Distillation and Hybrid System for Waterethanol Separation, Renewable Energy, 51, 310-316.

McCabe, W. L. (1993). Unit Operations of Chemichal Engineering $5^{\text {th }}$ edition. New York: McGraw Hill Book Company.

Millare, J. C., \& Basilia, B. A. (2019) Dispersion and Electrokinetics of Scattered Objects in Ethanol-water Mixtures, Fluid Phase Equilibria, 481, 44-54.

Muhammad, D. R. A., Darmadji, P., \& Pranoto, Y. (2011) Pengaruh Suhu Distilasi dan Tingkat Kondensor terhadap Sifat Sensoris Distilat Asap Cair, Jurnal Teknologi Hasil Pertanian, IV(2), 104-112.

Pan, Q., Shang, X., Li, J., Ma, S., Li, L., \& Sun, L. (2019) Energy-efficient Separation Process and Control 
Scheme for Extractive Distillation of Ethanol-water Using Deep Eutectic Solvent, Separation and Purification Technology, 219, 113126.

Parmitasari, P., \& Hidayanto, E. (2013) Analisis Korelasi Indeks bias dengan Konsentrasi Sukrosa beberapa Jenis Madu Menggunakan Portable Brix Meter, Youngster Physics Journal, 1(5), 191-198.

Ponce, G. H. S. F., Alves, M., Miranda, J. C. C., Filho, R. M., \& Maciel, M. R. W. (2015) Using an Internally Heat-Integrated Distillation Column for Ethanol-water Separation or Fuel Applications, Chemical Engineering Research and Design, 95, 55-63.

Quijada-Maldonado, E., Meindersma, G. W., \& Haan, A. B. (2014) Ionic Liquid Effects on Mass Transfer Efficiency in Extractive Distillation of Water-ethanol Mixtures, Computers and Chemical Engineering, 71, 210-219.

Spotar, S., Rahman, A., Gee, O. C., Jun, K. K., \& Manickam, S. (2015) A Revisit to the Separaton of a Binary Mixture of Ethanol-water Using Ultrasonic Distillation as a Separation Process, Chemical Engineeringand Processing: Process Intensification, 87, 45-50.

Sukasem, N., Hareemao, T., \& Sudawong, C. (2017) The Mimic of Fractional Distillation Technology for Development of Homegrown Pot Distillery for Ethanol Distillation, Energy Procedia, 138, 985-990.

Walangare, K. B. A., Lumenta, M. A. S., Wuwung, J. O., \& Sugiarso, B. A. (2013) Rancang Bangun Alat Konversi Air Laut Menjadi Air
Minum dengan Proses Distilasi Sederhana Menggunakan Pemanas Elektrik, e-jurnal Teknik Elektro dan Komputer UNSRAT, Manado.

Woldemariam, D., Kullab, A., Khan, E. U., \& Martin, A. (2017) Recovery of Ethanol from Scrubber-water by District Heat-driven Membrane Disillation : Industrial-scale Technoeconomic Study, Renewable Energy, 1-11.

Zhang, W., Xu, Z., Yang, X. (2019) Molecular Simulation of Penetration Separation for Ethanol/Water Mixtures Using Two-dimensional Nanoweb Graphynes, Chinese Journal of hemical Engineering, 27(2), 286292.

Zhao, L., Lyu, X., Wang, W., Shan, J., \& Qiu, T. (2017) Comparison of Heterogeneous Azeotropic Distillation and Extractive Distillation Methods for Ternary Azeotrope Ethanol/Toluene/Water Separation, Computers and Chemical Engineering, 100, 27-37. 